13

\title{
Фотостимуляция проводимости и электронные свойства автоэмиссионных наноуглеродных покрытий на кремнии
}

\author{
(C) А.В. Архипов, П.Г. Габдуллин, С.К. Гордеев, А.М. Журкин, О.Е. Квашенкина \\ Санкт-Петербургский политехнический университет Петра Великого, \\ 195251 Санкт-Петербург, Россия \\ e-mail: alezhu@inbox.ru
}

(Поступило в Редакцию 28 апреля 2016 г.)

Исследована электронная структура островковых углеродных пленок на кремнии, демонстрирующих способность к низковольтной полевой электронной эмиссии - при средней напряженности электрического поля от сотен $\mathrm{V} / \mathrm{mm}$. Методом туннельной спектроскопии показано, что островки таких покрытий характеризуются сплошным спектром разрешенных делокализованных состояний вблизи уровня Ферми, т.е. содержат углерод в $s p^{2}$-состоянии. Обнаружено явление фотопроводимости изучаемых покрытий. На основании исследования его токовых и спектральных характеристик показано, что островки отделены друг от друга туннельными барьерами, а от подложки - барьером Шоттки.

\section{Введение}

Благодаря высокой температуре испарения, химической инертности и устойчивости ко многим разрушающим факторам углерод уже в течение продолжительного времени считается перспективным материалом для холодных полевых эмиттеров электронов [1-13]. Такие его формы, как нанотрубки и графен (и подобные им наноленты, наноконусы, наносвитки и т.д.), позволяют практически достигать чрезвычайно высоких значений коэффициента усиления приложенного электрического поля $\beta$ и за счет этого получать эмиссионные токи при невысоких значениях прикладываемых напряжений [14]. Однако во многих случаях к низковольтной эмиссии электронов оказываются способны и многие виды наноуглеродных материалов, не содержащие (по крайней мере, на первый взгляд) морфологических элементов, способных обеспечивать эффективное „геометрическое усиление электрического поля. Несмотря на высокую распространенность данного явления, его природа остается окончательно не выясненной, о чем свидетельствует разнообразие предлагаемых моделей. Их можно найти, например, в оригинальных работах [15-23], а в систематизированном виде - в более ранних обзоpax [1-3,24-28]. Вместе с тем углеродные структуры, где высокая эмиссионная эффективность достигается не за счет высоких значений $\beta$, потенциально могут обладать существенными преимуществами. В случае острийных и лезвийных эмиттеров действия разрушающих факторов (тепловыделение, пондеромоторые силы электрического поля, ионная бомбардировка), как правило, экстремально сконцентрированы в ограниченных областях, обычно у эмитирующего участка поверхности. Если же усиление поля невелико, можно ожидать менее неоднородного распределения этих факторов, а значит, большей стабильности и долговечности эмиттеров.

Ранее [29-31] были опубликованы первые результаты наших исследований эмиссионных свойств островковых углеродных покрытий на кремниевых подложках, которые можно рассматривать как предельный, максимально упрощенный случай наноуглеродного материала. „Гладкая“ морфология поверхности углеродного покрытия лишена элементов, способных обеспечить существенное „геометрическое“ усиления приложенного электрического поля на вакуумной границе. Однако при определенных условиях покрытия демонстрировали способность в низковольтной эмиссии электронов - в полях, характеризуемых значениями средней напряженности порядка $1 \mathrm{~V} / \mu \mathrm{m}$. В настояшей работе представлены новые данные, в основном касающиеся воздействия оптического излучения на электронные и эмиссионные свойства таких систем.

Интерес к данному вопросу объясняется тем, что в процессе низковольтной эмиссии могут участвовать термодинамически неравновесные („горячие“) электроны. Создание дополнительных популяций таких электронов с помощью потоков излучения может быть полезным инструментом исследований природы изучаемого феномена. Возможно и практическое применение явления фотоактивированной полевой эмиссии, например для создания модулированных электронных потоков, возможность чего была продемонстрирована ранее для катодов на основе углеродных нанотрубок [32-35].

\section{1. Объект и методики исследований}

Изучавшиеся углеродные пленки наносились на подложки площадью около $1 \mathrm{~cm}^{2}$, изготавливавшиеся из стандартных пластин монокристаллического кремния различного типа проводимости, степени легирования и кристаллографической ориентации. Углерод наносился методом химического осаждения из газовой смеси, содержавшей ацетилен. В ходе процесса подложки поддерживались при температуре около $760^{\circ} \mathrm{C}$. Сoгласно результатам исследований с помощью атомносилового микроскопа (NanoDST производства Pacific Nanotechnology), покрытия имели островковую структуру (рис. 1). Поперечный размер островков составлял 



Рис. 1. АСМ изображения участка поверхности одного из образцов углеродного покрытия $(a)$ и отдельного островка $(b)$.

10-30 nm, а высота - несколько nm. Измерения, проведенные с помощью рентгеновского фотоэлектронного спектрометра (ESCA-5400, Perkin Elmer), не выявили присутствия на поверхности иных химических элементов помимо углерода, кремния и кислорода [29].

Приготовленные таким образом образцы островковых углеродных пленок можно рассматривать как типичные. Покрытия с аналогичной морфологией могут создаваться различными методами. К примеру, в работе [36] описана технология нанесения таких покрытий в СВЧ-плазме низкого давления. Помимо технологии, применявшейся в данной работе и ранее в [29], нами также были опробованы методы магнетронного распыления [31] и химического осаждения, активированного высокочастотным разрядом атмосферного давления [30]. Во всех случаях были получены покрытия со сходными морфологическими и эмиссионными параметрами.

Исследования эмиссионных свойств проводились нами в плоском зазоре шириной $0.6 \mathrm{~mm}$ с отбором тока на торец цилиндрического вольфрамового анода диаметром $6 \mathrm{~mm}$ в вакууме $(1-3) \cdot 10^{-5}$ Ра при комнатной температуре после обезгаживания при $200^{\circ} \mathrm{C}$.

Исследования локальной проводимости поверхности и плотности состояний образца вблизи уровня Ферми проводились с использованием вакуумного туннельного микроскопа SMM 2000 Vac (производства ПротонМИЭТ). Перед началом измерений вакуумный объем откачивался до давления остаточных газов не хуже $10^{-5} \mathrm{~Pa}$. Далее регистрировалось туннельное изображение поверхности, для нескольких точек которого измерялись ВАХ туннельного тока $I(U)$ при отключении обратной связи микроскопа. Первоначально измерения проводились для различных значений расстояния между зондом и поверхностью, определяемых „параметрами подвода“" $U_{0}$ и $I_{0}$. Чтобы исключить влияние сопротивления туннельного контакта на рассматриваемые ВАХ, расстояние последовательно уменьшалось до тех пор, пока вид зависимости $I(U)$ не переставал зависеть от параметров подвода. При этом сопротивление туннельного зазора можно считать пренебрежимо малым по сравнению с эффективным сопротивлением образца, а дифференциальное сопротивление $d I / d U$ - отражающим локальную плотность состояний его поверхности. В этом режиме для каждой исследуемой точки образца проводилось не менее 10 измерений ВАХ, результаты которых впоследствии усреднялись, чтобы исключить влияние случайных выбросов, связанных с флуктуациями величины туннельного зазора при отключенной обратной связи. Время записи каждой ВАХ равнялось приблизительно $500 \mathrm{~ms}$; оптимальные параметры подвода, как правило, составляли $I_{0}=1 \mathrm{nA}, U_{0}=1 \mathrm{~V}$.

При измерении характеристик поверхностной проводимости использовался стандартный четырехзондовый метод. Контактные площадки на поверхности образцов формировались с использованием проводящего клея на основе серебра (Heraeus РC 3231 или Контактол). При измерениях проводимости сквозь подложку омический контакт на ее задней поверхности создавался путем нанесения капель In-Ga эвтектики с механическим удалением оксидного слоя.

В качестве источников оптического излучения применялись инфракрасные светодиоды с длиной волны излучения 880, 940 и $953 \mathrm{~nm}$, а также лабораторные источники с излучением в видимом и УФ диапазонах. Спектральные характеристики фотопроводимости исследовались с помощью фурье-спектрометра Bruker Vertex 80v.

\section{2. Результаты эксперимента}

\section{1. Эмиссионные характеристики}

Многие из изученных образцов островковых углеродных покрытий, нанесенных по описанной выше технологии, демонстрировали способность к низковольтной эмиссии электронов. Одна из типичных токовых характеристик представлена на рис. 2 , другие приводились ранее в [29]. Большинство зависимостей имели приблизительно экспоненциальную форму. Значения порогового поля (соответствующие появлению эмиссионного тока $1 \mathrm{nA}$ ) для ряда образцов могли быть весьма низкими от $0.5 \mathrm{kV} / \mu \mathrm{m}$ [29]. Однако различия между образцами разных серий (а иногда и внутри серии) могли быть 


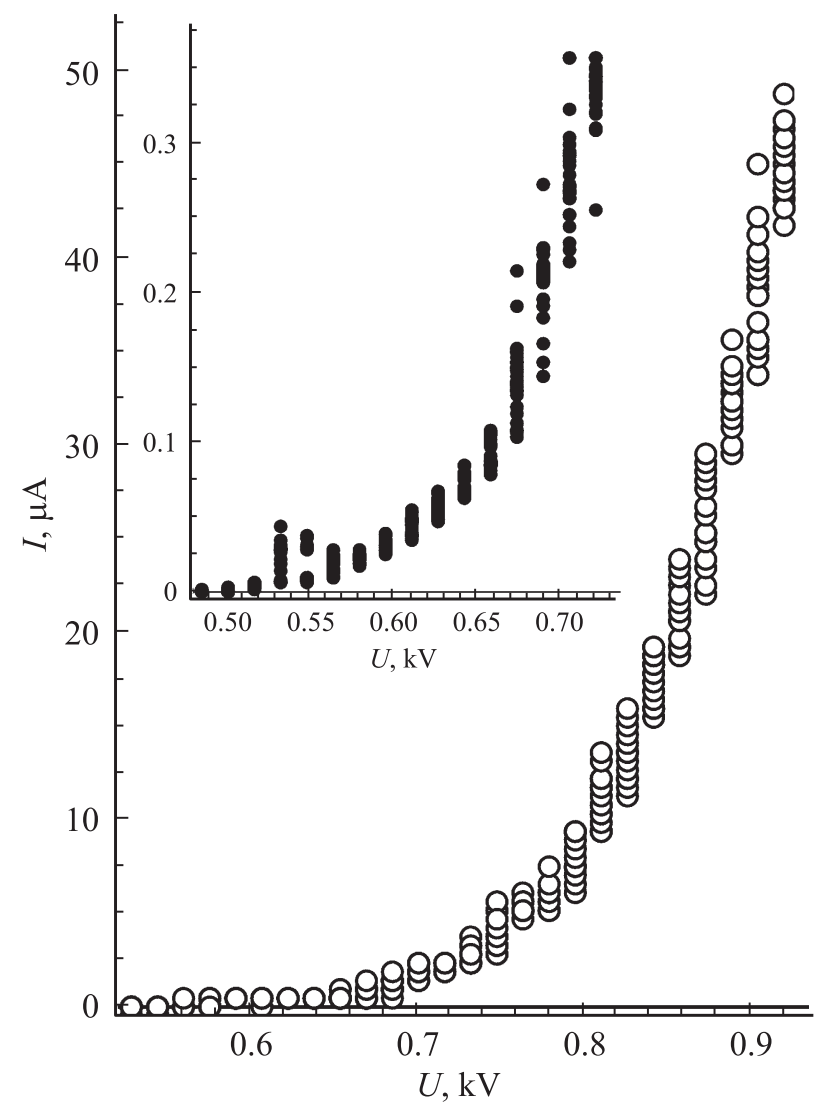

Рис. 2. Типичная эмиссионная характеристика образца эмиссионного покрытия на подложке КДБ10(100); на врезке участок вблизи порога эмиссии. очень существенными. Была отмечена закономерная корреляция эмиссионных свойств с морфологией покрытий, а также видом подложки. В частности, низковольтной эмиссии не наблюдалось, если перед нанесением покрытия с подложки удалялся оксидный слой. Самые низкие значения порогового поля были получены для покрытий на слаболегированных подложках с дырочной проводимостью (КДБ10), при этом зависимости эмиссионных свойств от кристаллографической ориентации поверхности замечено не было. Низковольтной эмиссии не наблюдалось для покрытий наибольшей эффективной толщины, характеризуемых высокой проводимостью измеряемыми значениями удельного сопротивления порядка единиц $\mathrm{k} \Omega \cdot \mathrm{cm}$ и менее.

Следует также отметить, что многочисленные попытки обнаружить изменение эмиссионных токов при освещении образца светом различной интенсивности и длины волны не дали результата - в частности, даже при использовании УФ лампы, излучающей в диапазоне $350-400 \mathrm{~nm}$ (энергия кванта до $\sim 3.5 \mathrm{eV}$ ). При освещении образцов светом ртутной лампы с энергией квантов до $\sim 10 \mathrm{eV}$ наблюдался эмиссионный ток, практически не зависевший от приложенного напряжения, который можно полностью отнести на счет фотоэлектронной эмиссии.

\section{2. Туннельные изображения и спектры}

Метод туннельной микро- и спектроскопии позволяет изучать электронные свойства вещества с привязкой к
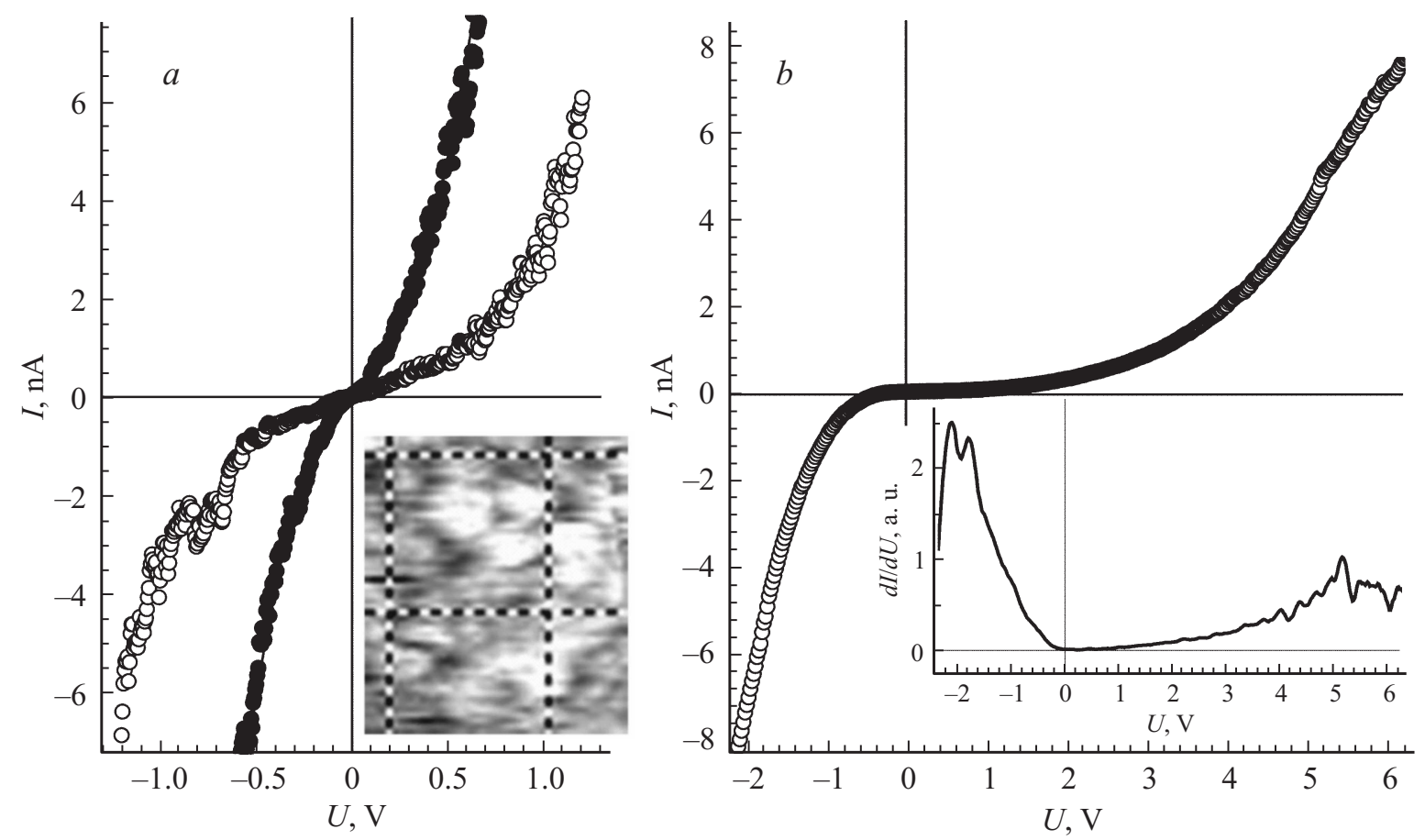

Рис. 3. Туннельные ВАХ для двух островков углеродного покрытия (a) и для промежутка между островками $(b)$. На врезках представлены соответственно туннельное изображение участка поверхности образца (размер клетки $100 \mathrm{~nm}$ ) и распределение плотности состояний, полученное дифференцированием приведенной туннельной ВАХ. 

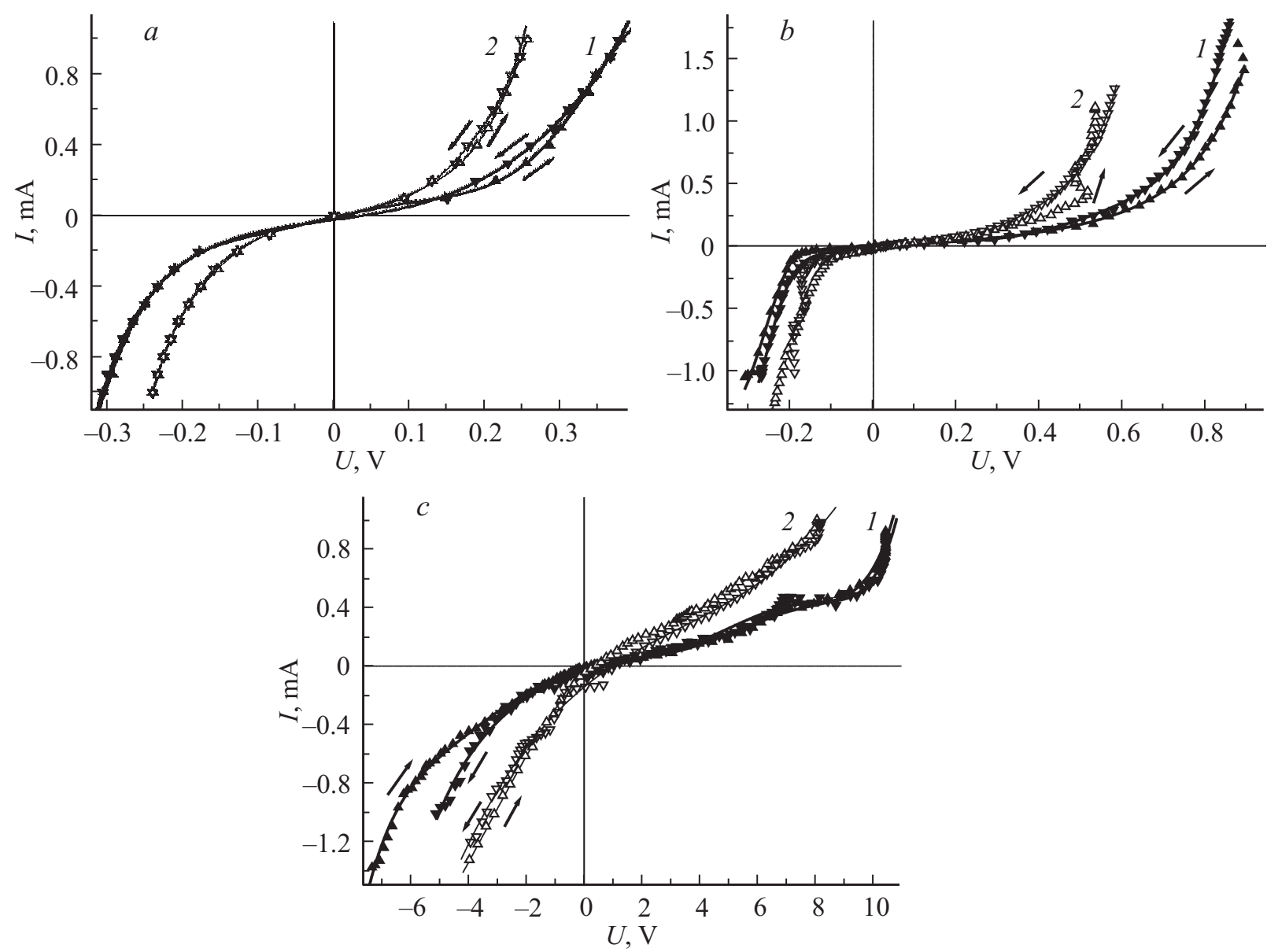

Рис. 4. Характеристики поверхностной проводимости углеродных покрытий в темноте (1) и при освещении (2). Покрытия сформированы на кремниевых подложках с собственной $(a)$, дырочной $(b)$ и электронной $(c)$ проводимостями. Стрелки указывают направление измерения каждой кривой.

конкретному объекту — такому как отдельный углеродный островок нанометровых размеров. Полученные туннельные изображения (на рис. 3, $a$ ) подтвердили данные АCM об островковой структуре покрытия, типичных размерах островков и плотности их расположения (данные рис. 1 и 3 относятся к одному образцу). Туннельные спектры, полученные для участков между островками (рис. $3, b)$, были идентичны спектрам для чистой подложки. Они отражали присутствие запрещенной зоны шириной порядка $1.2 \mathrm{eV}$ и асимметричное расположение в ней уровня Ферми. Аналогичные кривые, измеренные для островков (рис. 3,a), демонстрируют наличие сплошного спектра делокализованных разрешенных состояний в окрестности уровня Ферми. Таким образом, можно утверждать, что островки составлены углеродом в проводящем $s p^{2}$-состоянии и разделены участками чистой подложки (а не, к примеру, участками покрытия меньшей толщины).

В процессе проведения измерений было отмечено, что получение данных возможно лишь при освещении образца. При прекращении освещения туннельный ток постепенно уменьшался с характерным временем порядка нескольких секунд. Естественное объяснение такого явления может состоять в том, что в темновом режиме проводимость образца недостаточна для работы микроскопа, но при этом он обладает выраженным свойством фотопроводимости. Поскольку секундные значения времени релаксации нетипичны для фотопроводимости легированного кремния (скорее, следовало бы ожидать времен масштаба десятков наносекунд [37]), можно связать наблюдаемое явление с присутствием покрытия и рассчитывать на получение дополнительной информации об особенностях его электронной структуры путем исследования характеристик фотопроводимости.

\section{3. Поверхностная и объемная фотопроводимости образцов}

Наличие значительной фотостимулированной проводимости было экспериментально обнаружено у покрытий, нанесенных на подложки всех видов - с электронной, дырочной и собственной проводимостью.

При том, что сами нелегированные подложки при комнатной температуре были практически непроводящими, образцы сформированных на них углеродных покрытий обладали набольшей поверхностной проводимостью как 


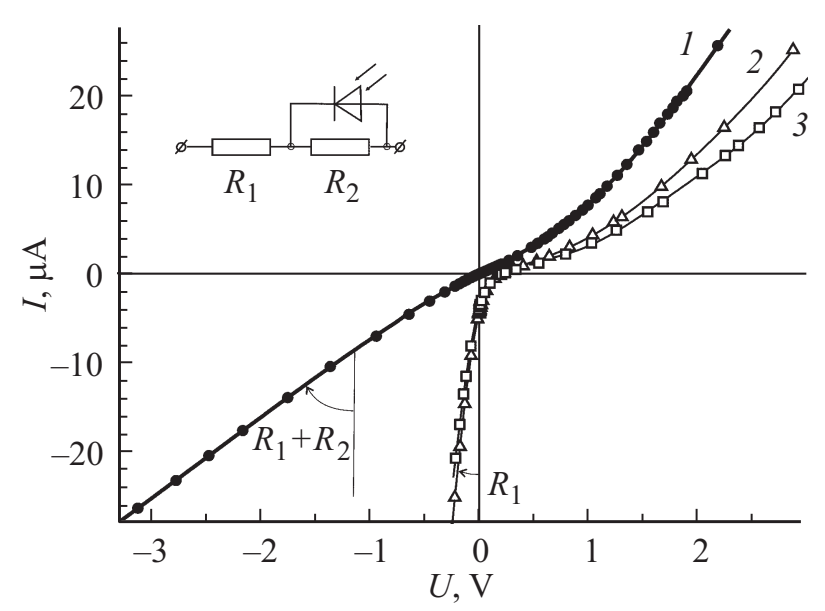

Рис. 5. Характеристики проводимости сквозь образец углеродного покрытия на подложке КЭФ 4.5 в темноте $(1)$ и при освещении ИК (2) и видимым (3) светом. Контакты размещены на покрытии и на противоположной стороне подложки.

в темновом режиме, так и при освещении. Токовые характеристики, имевшие нелинейный вид (рис. 4,a), отличались высокой стабильностью и повторяемостью при многократных измерениях, а также симметрией. При заданном значении напряжения ток монотонно возрастал с увеличением освещенности.

Протекание тока по покрытиям на легированных подложках (рис. $4, b, c)$ приводило к формированию значительно бо́льших разностей потенциалов. Их отличительными особенностями также были значительно большая нестабильность, худшая воспроизводимость при многократных измерениях, гистерезис, наличие скачков и ступенек. Форма зависимостей и степень их фоточувствительности (соотношение токов для темнового режима и при освещении) были примерно такими же, как и для образцов на нелегированных подложках.

Сами по себе токовые характеристики, измеренные с помощью контактов, размещенных на одной стороне образца, не позволяют судить о проводимости изучаемого покрытия, поскольку ток может протекать как вдоль покрытия, так и через объем подложки - если последняя не является диэлектрической. Для того, чтобы оценить вклад объемной проводимости в представленные выше результаты, были проведены измерения проводимости с использованием дополнительного омического контакта на противоположной стороне подложки. Типичные зависимости для образца на подложке с электронной проводимостью (КЭФ 4.5) представлены на рис. 5. Токи были стабильными, зависимости хорошо воспроизводились при многократных измерениях. При освещении образца по стороны углеродной пленки вид токовой зависимости существенно изменялся. В целом приведенную совокупность характеристик можно приближенно интерпретировать с помощью электрической схемы, показанной на врезке и состоящей из фотодиода и двух сопротивлений. Одно из них $\left(R_{1} \sim 10 \mathrm{k} \Omega\right)$ ограничивает ток обратной ветви при освещенном образце. Другое, значительно большее по величине $\left(R_{2} \sim 100 \mathrm{k} \Omega\right)$, определяет ток „утечки“ для темнового режима. Приведенные характеристики позволяют оценить величину фотоЭДС как 0.2-0.3 V. Полярность „фотодиода“ соответствует $p$-области со стороны углеродного покрытия.

Для получения более подробной информации было проведено измерение спектральных зависимостей фотоЭДС и фотопроводимости с использованием ИК фурьеспектрометра при низкой интенсивности излучения, значительно ниже уровня насыщения фотоЭДС. В первом случае в качестве регистрируемого спектрометром сигнала использовалась разность потенциалов между контактными площадками на различных сторонах образца, во втором - ток через образец при подаче постоянного смещения. Результаты измерений приведены на рис. 6. Измерения проводились для нескольких контактных площадок на образце углеродного покрытия на подложке КЭФ 4.5, а также на аналогичной „чистой““ подложке без углеродного покрытия, естественно окисленной.

На рис. 6, $а$ представлены спектральные характеристики фотоЭДС для различных участков образца с углеродным покрытием (аналогичные спектры для „чистой“
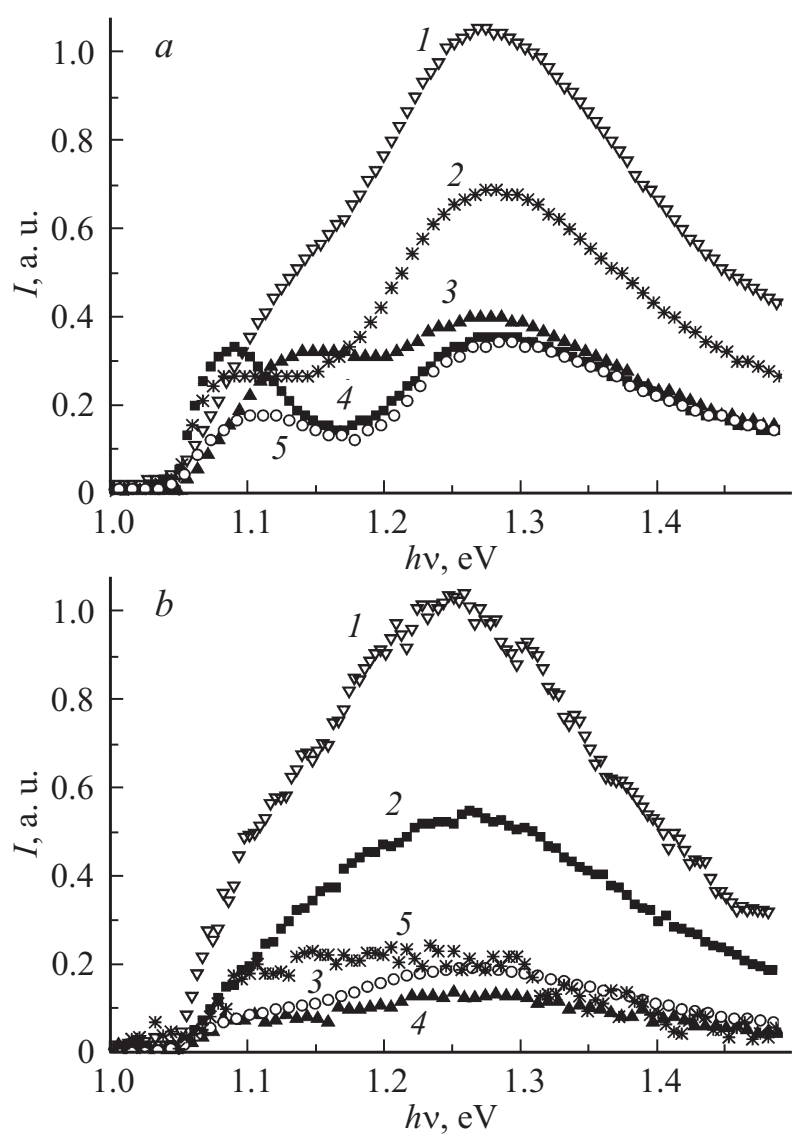

Рис. 6. Спектральные характеристики фотоЭДС $(a)$ и фотопроводимости $(b)$ для нескольких контактных площадок, нанесенных на образец углеродного покрытия на кремниевой подложке КЭФ 4.5. На графике для фотопроводимости представлен также спектр, полученный для чистой подложки без углеродного покрытия (кривая 5). 
подложки получить не удалось). Длинноволновый край области поглощения во всех случаях расположен вблизи величины энергии кванта $1.05 \mathrm{eV}$, что приблизительно соответствует положению примесных уровней фосфора относительно потолка зоны проводимости. В каждом из спектров можно выделить две составляющие, максимум одной из которых расположен вблизи значения, определяемого шириной запрещенной зоны кремния $1.12 \mathrm{eV}$, a другой - около $1.25-1.3 \mathrm{eV}$. Его сдвиг относительно края поглощения и первого пика приблизительно соответствует значению фотоЭДС насыщения, определяемого по графику рис. 5. Для разных контактных площадок соотношение величин двух составляющих было различным, но в целом можно отметить, что высокоэнергетический пик имел большую высоту. Его доминирование было наиболее выражено в спектрах сигналов наибольшей полной амплитуды (кривые 1,2).

Спектральные зависимости фотопроводимости, представленные на рис. $6, b$, характеризуются тем же положением длинноволнового края, что и зависимости для фотоЭДС. Однако здесь наблюдается лишь один широкий пик, форма которого универсальна для большинства контактных площадок при существенной разнице в величине полной амплитуды сигнала. Использование данной методики для получения спектральной зависимости фотопроводимости для большинства контактных площадок на подложке без углеродного покрытия не принесло результата. Единственное исключение представляет зависимость, приведенная на рис. $6, b$ как кривая 5. Полная амплитуда этого сигнала невелика. Положение низковольтного края его спектра не отличается от положения такой же границы для образца с покрытием, но единственный спектральный максимум имеет бо́льшую ширину и смещен в сторону меньших энергий на те же $\sim 0.15-0.2 \mathrm{eV}$. Таким образом, можно констатировать, что именно наличие покрытия приводит к дополнительной чувствительности по отношению к фотонам с повышенной энергией.

\section{3. Обсуждение экспериментальных результатов}

Полученные в работе экспериментальные данные о наличии сплошного спектра разрешенных состояний вблизи уровня Ферми изучаемого островкового углеродного покрытия представляются важными для установления структуры активного центра низковольтной эмиссии. Поскольку эти состояния поддерживают протекание тока с зонда туннельного микроскопа, они очевидно являются делокализованными и относятся к углероду в графитоподобной форме. Ранее для углеродных покрытий, создававшихся методами магнетронного распыления графита [31] и химического осаждения в разряде высокого давления [30], мы наблюдали радикальное улучшение эмиссионных свойств при отжиге образцов в вакууме при температурах $520-770^{\circ} \mathrm{C}$. Это изменение объяснялось трансформацией углерода из алмазоподобного в графитоподобное состояние, однако прямых доказательств этому в указанных работах получить не удалось. Теперь же мы имеем прямое подтверждение присутствия углерода именно в электропроводящем $s p^{2}$ состоянии.

Вместе с тем электронные свойства эмиттера определялись не только покрытием, но и видом подложки. Для случая подложки с электронной проводимостью наблюдение фотоЭДС (противоположные знаки напряжения и тока на рис. 5) прямо свидетельствует о формировании между покрытием и подложкой барьера Шоттки. Высоту этого барьера можно оценить как по максимальной наблюдаемой величине фотоЭДС, так и по ее спектральной зависимости (рис. 6,a) - по сдвигу в положении высокоэнергетического пика. Получаемая в обоих случаях оценка $(0.2-0.3 \mathrm{eV})$ хорошо коррелирует с разностью табличных значений работ выхода углерода $(\sim 4.7 \mathrm{eV})$ и $n$-кремния ( $4.4 \mathrm{eV})$ [38]. Отсутствие насыщения тока на обратной ветви темновой ВАХ рис. 5 и относительно малую величину „сопротивления утечки“ $R_{2} \sim 100 \mathrm{k} \Omega$ можно объяснить островковым характером нанесенного покрытия, предполагающим возможность формирования омического контакта на части его площади. При оценке влияния освещения на токовые зависимости следует принимать во внимание и следующую особенность данного эксперимента. Освещение производилось „сверху“, со стороны оптически непрозрачной контактной площадки, поэтому генерация дополнительных носителей заряда, обусловливающих протекание фототока, происходила лишь по периметру контакта, тогда как большая часть его площади оставалась неосвещенной.

Наблюдавшиеся при экспериментах с туннельным микроскопом большие времена последействия оптического излучения (порядка нескольких секунд) вполне согласуются с моделью изолированных обедненным слоем квантовых точек (островков). К примеру, в монографии [39] характерные времена жизни заряда на квантовых точках ртути в селене оценивались временами, сравнимыми со временем жизни Вселенной.

Наличие барьера между покрытием и подложкой помогает объяснить и результаты измерений поверхностной проводимости (рис. 4). При интерпретации таких результатов учитывают принципиальную возможность протекания тока как по поверхности образца (например, по покрытию), так и через его объем. Объемная проводимость самой подложки весьма велика - для условий эксперимента ее можно оценить величиной порядка $50 \mathrm{mS}$. Однако в обсуждаемом случае углеродного покрытия на подложке КЭФ 4.5 (рис. 4, b) между нанесенными на покрытие контактными площадками и объемом кремния присутствуют поверхностные переходы. При измерениях проводимости четырехзондовым методом лишь к одному из них будет приложено напряжение в прямом направлении, остальные окажутся „закрытыми“. Их темновую проводимость можно оценить величиной $1 / R_{2} \sim 10 \mu \mathrm{S}$. Представленная на рис. 4,c темновая 
BAX (кривая 1) при небольших значениях напряжения (менее $5 \mathrm{~V}$ ) приблизительно линейна и характерную проводимость можно оценить величиной $\sim 50 \mu \mathrm{S}$. Таким образом, вклад объемного канала распространения тока, скорее всего, не является доминирующим (хотя и может быть заметным). Это подтверждается и наблюдаемыми на данном графике признаками нестабильности и гистерезиса, не присущими, как видно из графиков рис. 5, токам через объем подложки. Таким образом, результаты измерения поверхностной проводимости в основном, по-видимому, характеризуют протекание тока по углеродному покрытию. Этот же вывод можно отнести и к образцам на подложках с дырочной и собственной проводимостью, где минимальный наклон зависимостей соответствует (рис. 4, $a, b$ ) значениям проводимости порядка 200 и $700 \mu \mathrm{S}$. Ограниченное влияние тока через подложку с дырочной проводимостью можно объяснить формированием и здесь контакта Шоттки, аналогичного ранее рассмотренному, но противоположной направленности (работа выхода р-кремния не ниже, а выше работы выхода углерода). Вид нелинейности приведенных на рис. 4 BAX, а также их сильная зависимость от освещенности соответствуют обычным характеристикам поверхностной проводимости покрытий, имеющих островковую структуру, где ток переносится туннелированием электронов между омически изолированными островками. Нестабильность и гистерезис токовых характеристик в этой модели можно связать с формированием на поверхности ограниченного числа путей протекания тока, представляющих собой соединяющие электроды цепочки островков, для которых электронный транспорт оказался наиболее эффективным. Распределение зарядов и потенциалов отдельных островков внутри такой „работающей“ цепочки устанавливается некоторым равновесным образом, обеспечивающим эффективный перенос заряда между электродами. „Включение“ или „выключение“ такой цепочки может иметь характер разового, дискретного события, определяемого физическими процессами на некоторых его критических участках - например, локального нагрева или десорбции загрязнений. При небольшом количестве токовых путей каждое такое событие может проявляться на ВАХ в виде участков с отрицательной дифференциальной проводимостью или гистерезиса, как в случае, иллюстрируемом рис. $4, b$.

Отдельного обсуждения заслуживает наблюдаемое соотношение характерных величин поверхностной проводимости для подложек различного типа. При одинаковых величинах напряжения проводимость покрытий на нелегированных, плохо проводящих подложках (рис. 5,a) в несколько раз превышала аналогичные значения для образцов на подложках с дырочной проводимостью и более чем на порядок - для образцов на подложках $n$-типа. Такая закономерность на первый взгляд представляется необычной. Однако результаты описанных выше экспериментов продемонстрировали наличие барьера Шоттки между покрытием и легированной подложкой, что означает существование в этой области слоя кремния, обедненного носителями. Его толщину $l_{d}$ можно оценить по известной формуле

$$
l_{d}=\left[\left(2 \varepsilon \varepsilon_{0} \phi\right) / e N\right]^{1 / 2},
$$

где $N$ - концентрация примеси (для использованных подложек $\sim 10^{15} \mathrm{~cm}^{-3}$ ), $\phi-$ высота барьера, которую можно оценить как $0.2-0.3 \mathrm{eV}$, что соответствует разности работ выхода подложки и покрытия и наблюдавшейся величине фотоЭДС (рис. 5). В результате получим толщину обеденного слоя $l_{d} \sim 0.5 \mu \mathrm{m}$, что значительно больше поперечного размера углеродных островков и расстояний между ними.

В случае нелегированной подложки из-за близости ее работы выхода к работе выхода углерода энергетический барьер между островками и подложкой формироваться не должен. В то же время определенное влияние может оказывать отличие обеих этих величин от работы выхода диоксида кремния $(4.4 \mathrm{eV})$, естественный слой которого при приготовлении образцов сознательно не удалялся. Из-за высокой проводимости графита барьер между ним и оксидом будет тонким и потому проницаемым для электронов. В то же время разность работ выхода оксида и собственного кремния, как известно [40], приводит к формированию в поверхностном слое последнего канала с существенной электронной проводимостью. В нашем случае присутствие углеродных островков, возможно, сделает его несплошным или даже неодносвязным. Однако его существование, вероятно, способно оказать влияние на проводимость покрытия (за счет переноса электронов по каналу или отдельным его участкам) или, по крайней мере, на величину емкости островков. Последнее обстоятельство может быть важным в рамках нескольких различных моделей проводимости.

Во-первых, емкость отдельных островков может влиять на условия формирования их цепочек, „включения“ и „выключения“ каналов проводимости, которые обеспечивают перенос заряда между электродами. Если данная модель верна и для формирования такого канала требуется (в какой-то форме) „пробой“ всех или некоторых туннельных промежутков в цепочке, емкости островков могут быть одним из параметров, определяющих порог развития такого процесса - подобно роли емкости „ускоряющих“ конденсаторов при работе генератора Маркса [41].

Возможен и другой механизм влияния емкости островков на поверхностную проводимость. Именно их емкостью определяется выполнение условий кулоновской блокады, которая принципиально способна затруднить туннелирование электронов между островками. Если считать, что островок отделен от проводящей подложки (или проводящего канала нелегированной подложки) слоем диоксида кремния $(\varepsilon \sim 4)$ толщиной $d=1 \mathrm{~nm}$ (типичное значение естественно окисленной пластины [42]), при поперечном размере островка $D=10 \mathrm{~nm}$ (рис. 1) в соответствии с формулой для емкости плоского конденсатора можно получить оценку $C \sim 10^{-18} \mathrm{~F}$. 
При этом порог кулоновской блокады $U_{c}=e / 2 C$ составит приблизительно $30 \mathrm{mV}$. Соответствующая ему энергия близка к значению $k T$ при комнатной температуре, а значит, соответствующий эффект, если и будет наблюдаться, окажется существенно подавлен из-за тепловых флуктуаций энергии электронов. При появлении у поверхности подложки обедненного носителями слоя (в случае легированных подложек) емкость островков окажется заметно меньшей. В качестве нижней оценки можно использовать формулу для емкости уединенного диска $C=4 \varepsilon \varepsilon_{0} D$ [43]. При том же диаметре $D=10 \mathrm{~nm}$ и ,компромиссном“ значении диэлектрической проницаемости $\varepsilon=3$ (островок расположен на границе с вакуумом) получим $C \sim 1 \cdot 10^{-18} \mathrm{~F}$ и $e U_{c}=e^{2} / 2 C \sim 100 \mathrm{meV}$, что уже существенно превышает энергетический эквивалент комнатной температуры. Следовательно, влияние явления кулоновской блокады на проводимость покрытия в данном случае может быть более существенным.

Явления в поверхностном слое подложки определяют, вероятно, и наблюдавшееся различие в эмиссионных свойствах покрытий, нанесенных на подложки различного типа проводимости. В случае нелегированного образца препятствием эффективной эмиссии электронов может служить высокое объемное сопротивление, затрудняющее транспорт электронов поверхности. В подложке с дырочной проводимостью внешнее электрическое поле с полярностью, требуемой для электронной эмиссии, формирует обедненный слой. В работе [30] нами было показано, что неоднородность свойств покрытия и самой подложки может при определенных условиях способствовать локальному усилению приложенного поля (рис. 7). Такая неоднородность может быть связана, к примеру, с дискретным характером распределения ионов примеси, среднее расстояние между которыми для используемых подложек имеет порядок $100 \mathrm{~nm}$, т. е. близко по величине как к типичной толщине обедненного слоя, так и к размеру островков покрытия. Присутствие кластеров таких ионов при распространении границы обедненного слоя от поверхности вглубь подложки должно приводить к искривлению этой границы, формированию на ней участков с высоким аспектными отношением (своего рода острий), где напряженность поля будет увеличенной. Наиболее сильный эффект был предсказан для случая, когда выступ границы обедненного слоя соседствует с островком покрытия, будучи отделенным от него лишь узким зазором. Концентрация поля на таком зазоре может приводить к инжекции в островок горячих электронов, способных к облегченной эмиссии из островка в вакуум. Изначальное присутствие у поверхности обедненного слоя у поверхности дырочной подложки, не учитывавшееся при проведении моделирования, не должно существенно изменить ситуацию, поскольку полное падение потенциала на этом слое, согласно экспериментальным оценкам, относительно невелико $(0.2-0.3 \mathrm{~V})$.

В картине явлений, иллюстрируемой рис. 7, перенос электронов к эмитирующим участкам через обедненный слой происходит по локальным токопроводящим

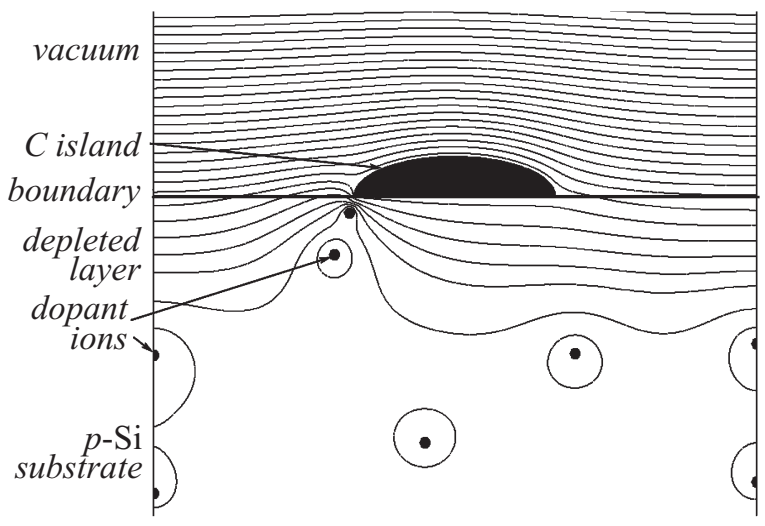

Рис. 7. Результат расчета распределения потенциала в обедненном слое кремния с дырочной проводимостью при приложении внешнего электрического поля. Учтены дискретное распределение ионов примеси и присутствие проводящего незаряженного островка на вакуумной границе. Показаны эквипотенциальные поверхности [30].

каналам. Ранее подобные процессы уже рассматривались применительно к эмиссионным свойствам углеродных и иных материалов [3,24-26,44-47]. Можно предположить, что в таких каналах будут генерироваться и неравновесные фононы, влияние которых на электронный транспорт внутри неоднородной среды и через ее вакуумную границу также окажется значительным - согласно данным и оценкам, приведенным в работах [15,16,48-53].

Дополнительным обстоятельством, облегчающим выход электронов в вакуум, может служить латеральная неоднородность поверхности образцов, приводящая к появлению „полей пятен“ [54-57]. Согласно изложенной в [54] модели, наличие на поверхности эмиттера разнородных по работе выхода, и следовательно, по электрическому заряду участков нанометрового размера приводит к тому, что электроны могут туннелировать из эмиссионных центров, характеризуемых наибольшей работой выхода, в области вакуума, расположенные напротив участков с низкой работой выхода. Проницаемость потенциального барьера, преодолеваемого такими электронами, оказывается наибольшей, что способствует повышенной эмиссионной способности неоднородных поверхностей. Помимо контактной разности потенциалов, причинами латерально-неоднородной зарядки поверхности могут быть вторичная электронная эмиссия [24,58] (можно найти сходство и с явлением малтеровской эмиссии [24,59]), а также приход ионов, образующихся при воздействии эмитированных электронов на остаточный газ. Такие ионы могут изменять заряд изолированных (не связанных с проводящими „каналами“) углеродных островков, увеличивая связанные с полями пятен потенциалы и делая эмиссию более эффективной. Возможность стимулирования эмиссии полями, связанными с зарядом газовых ионов, обсуждалась ранее в работе [60], где было рассмотрено, однако, лишь их 
влияние на потенциал самого эмиссионного центра, но не соседних с ним участков.

Таким образом, для островкового углеродного покрытия на подложке с дырочной проводимостью можно предложить по крайней мере три явления, способных внести вклад в улучшение эмиссионной способности: локальное усиление поля на границе обедненного слоя, неравновесный нагрев электронов в проводящих каналах и влияние „полей пятен“

Согласно полученным экспериментальным данным, в случае подложки с электронной проводимостью в отсутствие внешнего поля островки углеродного покрытия также изолированы обедненным носителями поверхностным слоем. Однако при приложении внешнего поля полярности, требующейся для отбора электронов, этот слой будет подавлен. Объем и поверхность эмиттера окажутся практически эквипотенциальными. Отсутствие эффектов усиления поля и „полей пятен“ в данном случае могут объяснить наблюдавшиеся в наших экспериментах худшие эмиссионные свойства покрытий на подложках $n$-типа.

Наблюдавшееся отсутствие фотостимуляции эмиссии в условиях, когда свет оказывал сильное воздействие на проводимость образцов, также позволяет сделать некоторые выводы о механизме низковольтной эмиссии для исследованных покрытий. К примеру, можно утверждать, что транспорт электронов к поверхности эмиттера не является ограничивающим эмиссию фактором. Отсутствие токов фотоэмиссии под действием излучения ИК, видимого и ближнего УФ диапазонов (вплоть до энергии квантов $\sim 3.5 \mathrm{eV}$ ) противоречит моделям, объясняющим низковольтную эмиссию локальным уменьшением работы выхода до значений ниже $1 \mathrm{eV}$. В то же время его можно интерпретировать в пользу модели горячих электронов - ведь если эмиссия определяется электронами, имеющими значительную избыточную энергию, сравнимую с работой выхода углерода $(\sim 4.7 \mathrm{eV})$, появление дополнительной термодинамически неравновесной популяции фотоэлектронов с заметно меньшей избыточной энергией может и не сказаться на эмиссионных токах.

\section{Выводы}

Таким образом, полученные данные о фоточувствительности электронных и эмиссионных свойств островковых углеродных покрытий на кремниевых подложках дают дополнительные свидетельства в пользу гипотезы, согласно которой активный центр холодной эмиссии электронов может представлять собой электрически изолированный наноразмерный домен углерода в графитоподобном состоянии (квантовую точку). Способность такого домена к низковольтной эмиссии определяется не пониженными значениями его работы выхода, а инжекцией горячих электронов, источником энергии которых является электрическое поле, проникающее в объем эмиттера.

\section{Список литературы}

[1] Xu N.S., Ejaz Huq S. // Materials Science and Engineering R: Reports. 2005. Vol. 48. N 2-5. P. 47-189.

[2] Railkar T.A., Kenq W.P., Windischmann H., Malshe A.P., Neseem H.A., Devidson J.L., Brown W.D. // Critical Reviews in Solid State and Materials Sciences. 2000. Vol. 25. N 3. P. 163-277.

[3] Carey J.D. // Phil. Trans. R. Soc. Lond. A. 2003. Vol. 361. P. 2891-2907.

[4] Fursey G.N. Field emission in vacuum microelectronics. NY: Kluwer Academic-Plenum Publishers. 2005. P. 205.

[5] Gulyaev Yu.V., Sinitsyn N.I., Torgashov G.V., Saveliev S.G. // Appl. Surf. Sci. 2003. Vol. 215. N 1-4. P. 141-148.

[6] Дюбуа Б.Ч., Королев А.Н. // Электронная техника. Серия 1: СВЧ-техника. 2011. № 1 (508). С. 5-24.

[7] Obraztsov A.N. // Nanoengineered Nanofibrous Materialas, Kluwer Acad. Publ., the Netherlands. 2004. P. 329-339.

[8] Krivchenko V.A., Pilevsky A.A., Rakhimov A.T., Seleznev B.V., Suetin N.V., Timofeyev M.A., Bespalov A.V., Golikova O.L. // J. Appl. Phys. 2010. Vol. 107. N 1. P. 014315.

[9] Obraztsov A.N., Kleshch V.I., Smolnikovam R.A. // Beilstain J. Nanotechnol, 2013. Vol. 4. P. 493-500.

[10] Kleshch V.I., Smolnikova E.A., Orekhov A.S., Kalvas Taneli, Tarvainen Olli, Kauppinen Janne, Nuottajarvi Antti, Koivisto Nannu, Janhunen Pekka, Obraztsov A.N. // Carbon. 2015. Vol. 81. P. 132-136

[11] Бугаев А.С., Ерошкин П.А., Романько В.А., Шешин Е.П. // УФН. 2013. Т. 183. С. 727-740.

[12] Ерошкин П.А., Шешин Е.П. // Нано- и микросистемная техника. 2014. № 1. С. 42-44.

[13] Суздальцев С.Ю., Шаныгин В.Я., Яфаров Р.К. // Письма в ЖТФ. 2011. Т. 37. Вып. 11. С. 91-98.

[14] Елецкий А.В. // УФН, 2010. Т. 180, № 9. С. 897-930.

[15] Рейх К.В., Эйдельман Е.Д., Вуль А.Я. // ЖТФ. 2007. Т. 77. Вып. 7. С. 123-126.

[16] Reich K.V., Eidelman E.D. // EPL (Europhysics Letters). 2009. Vol. 85. N 4. P. 47007.

[17] Frolov V.D., Konov V.I., Pimenov S.M., Kuzkin V.I. // Appl. Phys. A. 2004. Vol. 78. P. 21-23.

[18] Захидов Ал.А., Образцов А.Н., Волков А.П., Ляшенко Д.А. // ЖЭТФ. 2005. Т. 127. Вып. 1. С. 100-106.

[19] Kleshch V.I., Vasilieva E.A., Lyashenko S.A., Obronov I.V., Turnina A.V., Obraztsov A.N. // Phys. Stat. Sol. 2011. Vol. 248. N 11. P. 2623-2626.

[20] Баскин Л.М., Нейттаанмяки П., Пламеневский Б.А. // ЖТФ. 2010. Т. 80. Вып. 12. С. 86-89.

[21] Okotrub A.V., Bulusheva L.G., Kuznetsov V.L., Gusel'nikov A.V., Chuvilin A.L. // Applied Physics A: Materials Science \& Processing. 2005. N 2. P. 393-398.

[22] Яфаров Р.К. // ЖТФ. 2006. Т. 76. Вып. 1. С. 42- 48.

[23] Лобанов В.М. // ЖТФ. 2005. Т. 75. Вып. 11. С. 92-96.

[24] Forbes R.G. // Sol. St. Electron. 2001. Vol. 45. N 6. P. 779 808.

[25] Carey J.D., Forrest R.D., Poa C.H., Silva S.R.P. // J. Vac. Sci. Technol. B. 2003. Vol. 21. N 4. P. 1633-1639.

[26] Gupta S., Morell G., Weiner B.R. // J. Appl. Phys. 2004. Vol. 95. N 12. P. 8314-8320.

[27] Silva S.R.P., Amaratunga G.A.J., Okano K. // J. Vac. Sci. Technol. B. 1999. Vol. 17. N 2. P. 557-561. 
[28] Zhirnov V.V., Shenderova O.A., Jaeger D.L., Tyler T., Areshkin D.A., Brenner D.W., Hren J.J. // ФTT. 2004. T. 46. Вып. 4. C. 641-645.

[29] A.V. Arkhipov, P.G. Gabdullin, S.I. Krel, M.V. Mishin, A.L. Shakhmin, S.K. Gordeev, S.B. Korchagina S.B. // Fulleren. Nanotub. Carbon Nanostructur. 2012. Vol. 20. N 4-7. P. 468472

[30] Архипов А.В., Гнучев Н.М., Крель С.И. // Научнотехнические ведомости СПбГПУ. Физ.-мат. науки. 2012. № 4 (158). С. 98-103.

[31] Архипов А.В., Габдуллин П.Г., Гнучев Н.М., Емельянов А.Ю., Крель С.И. // Письма в ЖТФ. 2014. Т. 40. Вып. 23. С. 58-66.

[32] Yi-Chun Chen, Hsiu-Fung Cheng, Yun-Shuo Hsieh, YouMing Tsau // J. Appl. Phys. 2003. Vol. 94. N 12. P. 7739 7742.

[33] Hagmann M.J. // Proc. SPIE. 2004. Vol. 5352. P. 372-381.

[34] Guiset P., Combrie S., De Rossi A., Carras M., Schnell J.P., P. Legagneux P. // Proc. SPIE. 2008. Vol. 7037. P. 70370Q.

[35] Dispenza M., Brunetti F., Cojocaru C.-S., de Rossi A., Di Carlo A., Dolfi D., Durand A., A.M. Fiorello, Gohier A., Guiset P., Kotiranta M., Krozer V., Legagneux P., Marchesin R., Megtert S., Bouamrane F., Mineo M., Paoloni C., Pham K., Schnell J.P., Secchi A., Tamburri E., Terranova M.L., Ulisse G., Zhurbenko V. // Proc. SPIE. 2010. Vol. 7837. P. 783706.

[36] Ябаров Р.К., Шаныгин В.Я. // Письма в ЖТФ. 2014. Т. 40. Вып. 7. С. 8-15.

[37] Румянцев В.В., Морозов С.В., Кудрявиев К.Е., Гавриленко В.И., Козлов Д.В. // ФТП. 2012. Т. 46. Вып. 11. С. 1414 1418.

[38] Фоменко В.С. Эмиссионные свойства материалов. Киев: Наукова думка, 1981.

[39] Корсунский М.И. Аномальная фотопроводимость. М.: Наука, 1972. 192 с.

[40] 3и С. Физика полупроводниковых приборов. Т. 1. М.: Мир, 1984. $455 \mathrm{c}$.

[41] Месяи, Г.А., Насибов А.С., Кремнев В.В. Формирование наносекундных импульсов высокого напряжения. М.: Энергия, 1970. $155 \mathrm{c}$.

[42] Александров О.В., Дусь А.И. // ФТП. 2008. Т. 42. Вып. 11. C. $1400-14006$.

[43] Иоссель Ю.Я., Кочанов Э.С., Струнский М.Г. Расчет электрической емкости. Л.: Энергоиздат, 1981. 288 с.

[44] Latham R.V. // IEEE Transactions on Electrical Insulation. 1988. Vol. 23. N 1. P. 9-16.

[45] Ilie A., Hart A., Flewitt A.J., Robertson J., Milne W.I. // J. Appl. Phys. 2000. Vol. 88. N 10. P. 6002-6010.

[46] Kishore Uppireddi, WeinerB.R., Morell G. // J. Appl. Phys. 2008. Vol. 103. N 10. P. 104315.

[47] Koh A.T.T., Foong Y.M., Yu J., Chua D.H.C., Wee A.T.S., Kudo Y., Okano K. // J. Appl. Phys. 2011. Vol. 110. N 3. P. 034903.

[48] Dideykin A.T., Eidelman E.D., Vul A.Ya. // Sol. St. Commun. 2003. T. 126. № 9. C. 495 -498.

[49] Eidelman E.D., Vul' A.Ya.// J. Phys.. Condensed Matter. 2007. Vol. 19(7). P. 266 210-266 223.

[50] Рейх К.В., Эйдельман Е.Д. // ФТТ. 2011. Т. 53. Вып. 8. C. $1618-1620$.

[51] Мейлахс А.П., Эйдельман Е.Д. // Письма ЖЭТФ. 2014. T. 100. № 2. C. 89-93.
[52] Wei X.L. Golberg D., Chen Q., Bando Y.. Peng L.M. // Nano Lett. 2011. Vol. 11. N 2. P. 734-739.

[53] Wei Xianlong, Bando Yoshio, Golberg D. // ACS Nano. 2012. Vol. 6. N 1. P. 705-711.

[54] Cui J.B., Ristein J., Ley L. // Phys. Rev. 1999. Vol. 60. N 23. P. $16135-16142$.

[55] Robertson J. // J. Vac. Sci. Technol. B. 1999. Vol. 17. N 2. P. 659-665.

[56] Соминский Г.Г., Сезонов В.Е., Саксеев Д.А., Тумарева T.A. // ЖТФ. 2011. Т. 81. № 6. С. 104-108.

[57] Nose Kenji, Fujita Ryuhei, Kamiko Masao, Mitsuda Yoshitaka // J. Vac. Sci. Technol. 2012. Vol. 30. P. 011204.

[58] Geis M.W., Efremow N.N., Krohn K.E., Twichell J.C., Lyszczarz T.M., Kalish R., Greer J.A., Tabat M.D. // Nature. 1998. Vol. 393. P. 431-435.

[59] Добрецов Л.Н., Гомоюнова М.В. Эмиссионная электроника. М.: Наука, 1966. 564 с.

[60] Рейх К.В., Эйдельман Е.Д., Дидейкин А.Т., Вуль Ф.Я. // ЖТФ. 2008. Т. 78. Вып. 2. С. 119-122. 